\title{
The efficiency of cardiac biomarkers in the identification of patients with acute coronary syndrome
}

\begin{tabular}{cc}
\hline Sanaa Gadbaan Hama Almandlawi ${ }^{1 *}$ & Ajheen Muhammad Ali $^{\mathbf{1}}$ \\
\hline Abstract &
\end{tabular}

Background and objective: This study aimed to differentiate acute myocardial infarction from unstable angina upon the onset of chest pain, by evaluating the usefulness of combined biomarkers troponin I, ischemia modified albumin, and heart-type fatty acid binding protein as early as possible.

Methods: A cross-sectional study was conducted at the Department of Clinical Analysis, College of Pharmacy, Hawler Medical University. This study included 73 patients with suspected acute coronary syndrome, who attended to the Emergency and /or Cardiac Care Unit departments of Hawler Teaching Hospital and Rojhalat Emergency Hospital, Erbil, Iraq, and who were diagnosed with either acute myocardial infarction $(n=45)$ or unstable angina $(n=28)$ between 12 May 2013 and 25 January 2014. Serum troponin I, heart-type fatty acid binding protein, and ischemia modified albumin were determined twice, at between 30 minutes and 4 hours, and between 6 and 12 hours after the onset of chest pain.

Results: For diagnosing and differentiating between acute myocardial infarction and unstable angina, the sensitivity and specificity of serum troponin I cut-off value at $(\leq 4)$ hours of chest pain was $53.3 \%$ and $100 \%$, respectively. The sensitivity and specificity were $97.8 \%$ and 96.4 at $6-12$ hours after onset of chest pain. The sensitivity and specificity of heart-type fatty acid binding protein cut-off values at $(\leq 4)$ hours was $48.9 \%$ and $100 \%$, respectively, increasing to $84.4 \%$ and $100 \%$ at $6-12$ hours. The combined use of serum troponin I and heart-type fatty acid binding protein enhanced sensitivity to $73.3 \%$ at the first interval, and $100 \%$ at the second.

Conclusion: A combination of troponin I and heart-type fatty acid binding protein tests improves sensitivity in diagnosing and differentiating acute myocardial infarction and unstable angina within the first 4 hours of chest pain.

Keywords: Heart-type fatty acid binding protein; Ischemia modified albumin; Myocardial infarction; Troponin I; Unstable angina.

\section{Introduction}

In the United States each year, approximately 1.5 million out of 5 million people who attend emergency departments for chest pain and related symptoms, are hospitalized for acute coronary syndrome. ${ }^{1}$ Frequently, ECG yields inconclusive results, and the clinical symptoms are unreliable for diagnosis of myocardial infarction. Therefore, there is a clear need for employing serum biochemical markers to confirm a diagnosis of myocardial injury. ${ }^{2}$
A simple, rapid diagnostic test for cardiac ischemia - which is a critically important indication of the risk of future cardiac events - would be a valuable diagnostic tool in such a situation. Tests for heart-type fatty acid binding protein (H-FABP) and ischemia modified albumin (IMA) appear particularly promising for this use. ${ }^{3}$ IMA is considered a 'gold standard' screening method candidate marker for the detection of myocardial ischemia as part of patient evaluation. ${ }^{4} \mathrm{H}-\mathrm{FABP}$ is released early

${ }^{1}$ Department of Internal Clinical Analysis, College of Pharmacy, Hawler Medical University, Erbil, Iraq.

* Correspondence: sanaahama66@gmail.com 
into the plasma in cases of ischemia and/or myocardial injury, and a single measurement of this biomarker is regarded as highly sensitive and specific, allowing for prompt detection of emergency patients who are unsuitable for early discharge. ${ }^{5}$ ECG indicates diagnostic change in approximately $45 \%$ of patients who are diagnosed as having MI. Furthermore, typical clinical signs of ischemia are absent in one third of myocardial infarction cases. $^{6,7}$ It appears, therefore, that the best approach would be to integrate ECG assessment with results on biochemical cardiac markers to improve the triage process and to avoid the premature discharge of patients whose presentation is unclear. This study aimed to ascertain the efficiency of these cardiac markers in the early diagnosis of, and differentiation between, patients with myocardial infarction and those with unstable angina, attending Emergency Departments and Cardiac Care Units.

\section{Methods}

This cross-sectional study was conducted at the Department of Clinical Analysis, College of Pharmacy, Hawler Medical University, Erbil, Iraq. Seventy three patients were selected with acute coronary syndrome attending the Emergency and/or Cardiac Care Unit (CCU) departments of Hawler Teaching Hospital and the CCU of Rojhalat Emergency Hospital, from 12 May 2013 to 25 January 2014.

\section{Patients}

Patients with ischemic chest pain, ST elevation, and unstable angina pectoris were diagnosed according to changes in ECG and cardiac enzymes (troponin I, CK-MB). The patients were classified into two groups. The first group included individuals with unstable angina who had chest pain at rest lasting for more than 10 minutes, with ECG changes including ST segment depression $>0.5 \mathrm{~mm}$ and /or Dynamic $T$ wave inversion. The second group included those with myocardial infarction who had severe chest pain with or without radiation, and ST-elevation in at least two adjacent pericardial leads, $>1 \mathrm{~mm}$ in standard leads. The diagnosis was made by the cardiologist using all available clinical data, including patient histories and signs and symptoms, 12-lead ECGs, and cardiac markers (troponin, CK-MB).

\section{Study protocol}

The protocol specified early diagnosis patients with the acute coronary syndrome, assigned to early conservative treatment strategies, from both groups - the first within 30 minutes to 4 hours of the onset of chest pain; and the second within 6 to 12 hours of chest pain onset - to examine changes in serum IMA, H-FABP, and troponin I.

\section{Inclusion criteria}

Patients of both genders receiving care at the Emergency department, CCU, of the hospitals, with typical chest pain, and ECG changes suggestive of acute coronary syndromes within 30 minutes to 4 hours of onset.

\section{Exclusion criteria}

Exclusion criteria were: renal failure, liver failure, active malignancy, skeletal muscle injury, stroke, septic shock, congestive heart failure, heart disease unrelated to the acute coronary syndrome.

The study was approved by the Ethics Committee of Hawler Medical University, College of Pharmacy. All patients agreed to participate and gave their informed consent.

\section{Statistical analysis}

The statistical package for the social sciences (version 22) was used for data analysis. Statistical significance of mean difference (changes attributed to time interval) of a normally distributed quantitative outcome variable was assessed using the paired t-test, while ANOVA test was used for comparing more than two groups. The Chi-square $\left(X^{2}\right)$ test was used to test the statistical significance of the association between two categorical variables (presented on nominal or ordinal scales). A statistical significance level of 
$P<0.05$ was assumed. All analyzed tests were bilateral.

\section{Receiver Operating Characteristic Curve (ROC) definition}

ROC analysis provides a tool for the selection of optimal models and for discarding suboptimal ones, independently from (and prior to specifying) the cost context or the class distribution. ROC analysis is related in a direct and natural way to cost/benefit analysis in diagnostic decision making. This method allows for the selection of a typical cut-off value, which results in a highly valid test (highly specific, and with reasonably high sensitivity) through the ROC curve. The area beneath the curve suggests the usefulness of the test and facilitates comparison with other tests, with the proximity of the area indicating validity. The larger the area under the curve is (i.e., the closer to 1 ), the more valid the test since there is a considerable gain in sensitivity for minimal losses in specificity.

\section{Test performance characteristics}

The criteria for performance - or 'validity' of a test include the issues of sensitivity, specificity, positive predictive value, and negative predictive value. 'Sensitivity' relates to the conditional probability that a diseased person will have a positive result. Its value can be changed by changing the cut-off point for positive test results. 'Specificity' is the conditional probability that a disease-free person will yield a negative test result. The proportion of false negatives is the conditional probability that a diseased person will have a negative result (it equals 1-sensitivity); and the proportion of false positives is the conditional probability that a disease-free person will have a positive test result. Positive Predictive Value (PPV) describes the conditional probability that a person with a positive test result is actually diseased. Its value depends on the cut-off point for a positive test result and the prevalence of the disease in the screened population. Negative Predictive Value (NPV) describes the conditional probability that a person with a negative test result is actually free of the disease. 'Accuracy' (percent agreement) is the proportion of 'true' results occurring, taking all test results (positive and negative) into account. $^{8}$

\section{Results}

The results presented in this study were based on analysis of two study groups with a history of ischemic heart disease: $(n=28)$ individuals with unstable angina, with a mean age (mean \pm SD) of (59.25 \pm 2.3) years; and those with myocardial infarction $(n=45)$, with a mean age (mean \pm SD) of $(60.97 \pm 2.2)$ years. As shown in Table 1, no statistical difference was observed in mean ages. However, there was a statistically significant difference in gender distribution between the two study groups, with a higher percentage $(60 \%)$ of females in the unstable angina group; and significantly more males $(68 \%)$ in the acute myocardial infarction group, $P<0.05$.

Table 1: Comparing the relative frequency of age and gender between unstable angina and acute myocardial infarction groups.

\begin{tabular}{lccc}
\hline Study variables & Unstable angina $(\mathbf{n}=\mathbf{2 8})$ & Acute MI $(\mathbf{n}=\mathbf{4 5})$ & $\boldsymbol{P}$ value \\
\hline Age group (years) & $59.25 \pm 2.26$ & $60.9 . \pm 2.23$ & 0.430 \\
Mean \pm SD & & & 0.013 \\
Gender & $17(60.7 \%)$ & $14(31.1 \%)$ & \\
Female & $11(39.3 \%)$ & $31(68.9 \%)$ & \\
Male & $28(100.0 \%)$ & $45(100.0 \%)$ & \\
Total & & \\
\hline
\end{tabular}


All study biomarkers were estimated at two different intervals (30 mins $-4 \mathrm{hrs}$ and 6-12 hrs of chest pain onset). As shown in Table 2, there was no statistically significant difference in mean measurements of troponin I between the two study intervals in the unstable angina group $(0.4 \mathrm{ng} / \mathrm{ml}$ versus $0.2 \mathrm{ng} / \mathrm{ml})$, at $P>0.05$. In contrast, the difference in the mean concentration of troponin I did reach high statistical significance between the study intervals in acute myocardial infarction $(1.7 \mathrm{ng} / \mathrm{ml}$ versus $13.4 \mathrm{ng} / \mathrm{ml}$ respectively), at $P<0.001$. The mean of troponin I concentration was significantly higher in the acute myocardial infarction group, compared to the unstable angina group in both study intervals, at 1.7 $\mathrm{ng} / \mathrm{ml}$ versus $0.4 \mathrm{ng} / \mathrm{ml}$ respectively in the first study interval, and $13.4 \mathrm{ng} / \mathrm{ml}$ versus $0.2 \mathrm{ng} / \mathrm{ml}$ respectively in the second, with a significance of $P<0.001$. The results for ischemia modified albumin (IMA), as shown in Table 3 , showed no statistically significant difference in mean concentrations between the study intervals, for the unstable angina group $(19.8 \mathrm{ng} / \mathrm{ml}$ versus $18.4 \mathrm{ng} / \mathrm{ml}$ respectively), at $P>0.05$. The difference in mean concentrations of IMA was highly significant between study intervals in the acute myocardial infarction group, however, at $18.4 \mathrm{ng} / \mathrm{ml}$ versus $16.6 \mathrm{ng} / \mathrm{ml}$, respectively $(P<0.05)$.

Table 2: The changes in serum troponin-I after 6-12 hours compared to baseline values ( $\leq 4$ hours) within and between study groups.

\begin{tabular}{|c|c|c|c|}
\hline \multirow[t]{2}{*}{ Study groups } & \multicolumn{2}{|c|}{ Troponin-I(ng/ml) } & \multirow{2}{*}{$\begin{array}{c}P \text { (Wilcoxon) } \\
\text { (sign rank test) } P \text { value } \\
\text { (paired t-test) }\end{array}$} \\
\hline & first 4 hours & (6 to12 hours) & \\
\hline \multicolumn{4}{|l|}{ Unstable angina } \\
\hline Range & (0 to 1.2$)$ & (0 to 1.4$)$ & \\
\hline Mean \pm SD (Troponin I) & $0.4 \pm 0.23$ & $0.2 \pm 0.17$ & 0.140 \\
\hline $\mathrm{N}$ & 28 & 28 & \\
\hline \multicolumn{4}{|l|}{ Acute MI } \\
\hline Range & (0.1 to 175$)$ & (0.7 to 167$)$ & \\
\hline Mean \pm SD (Troponin I) & $1.7 \pm 0.9$ & $13.4 \pm 2.5$ & $<0.001$ \\
\hline $\mathrm{N}$ & 45 & 45 & \\
\hline $\begin{array}{l}P \text { (t-test) for difference in Mean } \\
\text { between } 2 \text { groups }\end{array}$ & $<0.001$ & $<0.001$ & \\
\hline
\end{tabular}

Table 3: The changes in serum Ischemia modified albumin (IMA) after 6-12 hours compared to its baseline values ( $\leq 4$ hours) within and between study groups.

\begin{tabular}{lccc}
\hline $\begin{array}{l}\text { Ischemia modified albumin(ng/ml) } \\
\text { Column title? Col Study groups }\end{array}$ & first $\mathbf{4}$ hours & (6 to $\mathbf{1 2}$ hours) & $\boldsymbol{P}$ value (paired t-test) \\
\hline $\begin{array}{l}\text { Unstable angina } \\
\text { Mean } \pm \text { SD }\end{array}$ & $19.8 \pm 3.35$ & $18.4 \pm 4.26$ & 0.210 \\
$\mathrm{~N}$ & 28 & 28 & \\
Acute MI & & & \\
Mean \pm SD & $18.4 \pm 3.88$ & $16.6 \pm 3.24$ & 0.013 \\
$\mathrm{~N}$ & 45 & 45 & \\
$P$ (t-test) for difference in mean & $0.12 \mathrm{NS}$ & 0.044 & \\
between 2 groups & & & \\
\hline
\end{tabular}


The mean concentration of IMA was higher to a statistically significant degree in the second study interval (6-12 hrs) in the unstable angina group compared to the acute myocardial infarction group (18.4 ng/ $\mathrm{ml}$ versus $16.6 \mathrm{ng} / \mathrm{ml}$ respectively), at $P<0.05$. As shown in Table 4, statistically significant higher mean concentrations of $\mathrm{H}-\mathrm{FABP}$ were found in the AMI compared to the unstable angina group, in both study intervals, at $10.5 \mathrm{ng} / \mathrm{ml}$ versus $5.6 \mathrm{ng} / \mathrm{ml}$ respectively in the first time interval, and $16.4 \mathrm{ng} / \mathrm{ml}$ versus $5.2 \mathrm{ng} / \mathrm{ml}$ respectively in the second, at $P<0.001$ significance. No statistically significant difference in H-FABP levels was found in the unstable angina group between the two intervals $(P>0.05)$. Use of the ROC curve in assessing the biomarkers in both study intervals, for differentiating acute myocardial infarction from unstable angina

All study biomarkers were tested for their validity in diagnosing and differentiating acute myocardial infarction from unstable angina, by examining the area under the receiver operating characteristic (ROC) curve and its statistical significance ('significance' being higher than the 0.5 ROC area of an equivocal test). As shown in table 5 , there was a highly statistically significant larger area under the ROC curve for troponin I, in both study intervals: 0.82 for the first and 0.994 for the second $(P<0.001)$. The area for heart type fatty acid binding protein (H-FABP) was associated with ROC area of (0.768) in the first study interval and (0.942) in the second, and also showed a statistically significant difference from the 0.5 area of the equivocal test $(P<0.001)$.

Table 4: The changes in serum Heart-type fatty-acid binding protein (H-FABP)-after 6-12 hours compared to its baseline values ( $<4$ hours) within and between study groups.

\begin{tabular}{lccc}
\hline $\begin{array}{l}\text { Heart type fatty acid binding protein (H-FABP) }(\mathrm{ng} / \mathrm{ml}) \\
\text { Study groups }\end{array}$ & first $\mathbf{4}$ hours & $\mathbf{( 6}$ to $\mathbf{1 2}$ hours) & $\boldsymbol{P}$ value (paired t-test) \\
\hline $\begin{array}{l}\text { Unstable angina } \\
\text { Mean } \pm \text { SD }\end{array}$ & $5.6 \pm 2.92$ & $5.2 \pm 2.46$ & 0.52 \\
$\mathrm{~N}$ & 28 & 28 & \\
$\begin{array}{l}\text { Acute MI } \\
\text { Mean } \pm \text { SD }\end{array}$ & $10.5 \pm 6.08$ & $16.4 \pm 9.92$ & $<0.001$ \\
$\mathrm{~N}$ & 45 & 45 & \\
$\mathrm{P}$ (t-test) for difference in mean & $<0.001$ & $<0.001$ & \\
between 2 groups & & & \\
\hline
\end{tabular}

Table 5: ROC area for selected biochemical measurements when used as test to predict acute MI differentiating it from unstable angina.

\begin{tabular}{lcc}
\hline Study biomarkers & AUC & $P$ value \\
\hline troponin I-(6 to 12 hours) & 0.994 & $<0.001$ \\
Heart-type fatty-acid binding protein (H-FABP)-(6 to 12 hours) & 0.942 & $<0.001$ \\
troponin I-first 4 hours & 0.820 & $<0.001$ \\
Heart-type fatty-acid binding protein (H-FABP)-first 4 hours & 0.768 & $<0.001$ \\
Ischemia modified albumin (IMA)-first 4 hours & 0.624 & 0.08 \\
Ischemia modified albumin (IMA)-(6 to 12 hours) & 0.602 & 0.14 \\
\hline
\end{tabular}


This larger area indicates greater validity in predicting and differentiating AMI from unstable angina (Table 6) for serum troponin I in the first 4 hours post-onset of chest pain. The optimum cut-off value, associated with the highest Matthew's correlation coefficient (MCC) (0.552), is $\geq 1.25 \mathrm{ng} / \mathrm{ml}$ - this means the subject is anticipated to have AMI if their serum troponin I concentration is $1.25 \mathrm{ng} / \mathrm{ml}$ or higher. A positive test at $\geq 1.25 \mathrm{ng} / \mathrm{m}$ value is associated with a sensitivity of $53.3 \%$ and specificity of $100 \%$. In a clinical setting, where the chances of a diagnosis of AMI are anticipated to be equal (50:50), given a positive test, one can expect $\mathrm{AMI}$ with a confidence of $100 \%$. Testing negative less than cut-off value $(1.25 \mathrm{ng} / \mathrm{ml})$ in the pretest probability condition (10\%) can exclude the probability of $\mathrm{Ml}$ with a confidence level of $95.1 \%$. Thus, measuring serum troponin $I$ in the first 4 hours post-onset, within the optimum cut-off value $(1.25 \mathrm{ng} / \mathrm{ml})$, can distinguish only $53.3 \%$ of patients with $\mathrm{AMI}$ - meaning $46.7 \%$ with $\mathrm{AMI}$ will give false negatives in the first interval. As shown in Table 5, $\mathrm{H}-\mathrm{FABP}$ was associated with a ROC area of $(0.768)$ and was statistically significantly different from the 0.5 area of the equivocal test $(P<0.001)$. Table 6 shows the optimum cut-off value of this test, which is associated with (0.518) MCC; the subject is expected to have AMl (as opposed to unstable angina) if they have a $\mathrm{H}-\mathrm{FABP}$ test of $10.05 \mathrm{ng} / \mathrm{ml}$ or higher. A positive test within this cut-off value is associated with $48.9 \%$ sensitivity and $100 \%$ specificity. In clinical situations where the probability of AMI in the first study interval is $50 \%$, given a positive test, AMl (as opposed to unstable angina) can be expected, with a confidence level of $100 \%$. Testing negative with a pretest probability of $10 \%$ can exclude the probability of having AMI with a confidence level of $94.6 \%$. The test for troponin I at 6-12 hours, at the highest MCC (0.942), the optimum cut-off value, was $(\geq 1.15 \mathrm{ng} / \mathrm{ml})$; this is $97.8 \%$ sensitive and $96.4 \%$ specific, as shown in Table 6 . Testing positive at this cut-off value would establish the diagnosis of acute MI with $96.5 \%$ confidence, in clinical situations, when the expectation is $50 \%$ of AMI rather than unstable angina. When the diagnosis of AMI is highly probable $(90 \%$ pretest probability) based on clinical symptoms, the confidence level of a positive result is further increased to $99.6 \%$. Testing negative with a pretest probability of $10 \%$ excludes the diagnosis of AMI with a confidence level of $99.7 \%$.Table 6 also shows the optimum cut-off value for $\mathrm{H}-\mathrm{FABP}$ associated with the highest MCC $(0.822)$ in the second study interval, which is $(\geq 9.15 \mathrm{ng} / \mathrm{ml})$, where the subject is expected to have AMI rather than UA. A positive test at this cut-off value establishes the diagnosis of AMI (as opposed to UA) with $84.4 \%$ sensitivity and

Table 6: Validity parameters for troponin I and H-FABP in both study time interval when used as test to predict acute MI differentiating it from unstable angina.

\begin{tabular}{|c|c|c|c|c|c|c|c|}
\hline \multirow[t]{2}{*}{$\begin{array}{l}\text { Positive if } \geq \\
\text { cut-off value }\end{array}$} & \multirow[t]{2}{*}{ Sensitivity } & \multirow[t]{2}{*}{ Specificity } & \multirow[t]{2}{*}{ Accuracy } & \multirow{2}{*}{$\begin{array}{l}\text { Matthews } \\
\text { correlatin } \\
\text { coefficient }\end{array}$} & \multicolumn{2}{|c|}{$\begin{array}{c}\text { PPV at pretest } \\
\text { probability = }\end{array}$} & \multirow{2}{*}{$\begin{array}{c}\text { NPV at pretest } \\
\text { probability = } \\
10 \%\end{array}$} \\
\hline & & & & & $50 \%$ & $90 \%$ & \\
\hline \multicolumn{8}{|l|}{ First 4 hours } \\
\hline Tropl $\geq 1.25$ & 53.3 & 100.0 & 71.2 & 0.552 & 100.0 & 100.0 & 95.1 \\
\hline $\begin{array}{l}\text { H-FABP } \\
\geq 10.05\end{array}$ & 48.9 & 100.0 & 68.5 & 0.518 & 100.0 & 100.0 & 94.6 \\
\hline \multicolumn{8}{|l|}{$\begin{array}{l}6 \text { to } 12 \text { hours } \\
\text { Tropl }\end{array}$} \\
\hline$\geq 1.15$ & 97.8 & 96.4 & 97.3 & 0.942 & 96.5 & 99.6 & 99.7 \\
\hline $\begin{array}{l}\text { H-FABP } \\
\geq 9.15\end{array}$ & 84.4 & 100.0 & 90.4 & 0.822 & 100.0 & 100.0 & 98.3 \\
\hline
\end{tabular}


$100 \%$ specificity. In clinical situations, where the expectation is of AMI, as opposed to UA, is at a pretest probability of $50 \%, 90 \%$; given a positive test one can expect AMI with a confidence level of $100 \%$ for a $50: 50$ chance; and at $100 \%$ for a pretest probability of $90 \%$. Testing negative in with a pretest probability of $10 \%$ excludes a diagnosis of AMI with a confidence level of $98.3 \%$.

Predicting acute myocardial infarction and differentiating it from unstable angina by assessing a combination of study biomarkers, at both study intervals:

It is apparent that a combination of cTnl and H-FABP can be considered to generate a positive test when one or both are positive. In both study intervals, the improvement is mainly in sensitivity, which was $73.3 \%$ at 30 mins- 4 hrs. where the sensitivity was $53.3 \%$ for troponin I, and $48.9 \%$ for H-FABP when each one was used without other(see Table 6), and 100\% at 6-12 hrs post-onset of chest pain, since the specificity of the component tests was already high $(100 \%$ for the first interval; and $96.4 \%$ for the second - see Table 7 ). A combination of using troponin I and $\mathrm{H}-\mathrm{FABP}$ is most valid and can be regarded as reliable, for both study intervals, in diagnosing and differentiating acute myocardial infarction from unstable angina.
The ischemia modified albumin test shows no statistically significant area by ROC analysis, and thus can be considered of lesser importance in this context.

\section{Discussion}

It is suggested that the measurement of cardiac biomarkers for myocardial injury plays an important role in the diagnosis and treatment of acute coronary syndrome. Each of the three key biomarkers will now be discussed briefly in this regard.

\section{Troponin I}

Cardiac troponin is considered the "gold standard' for the diagnosis of the acute coronary syndrome. In the present study, serum troponin I $(0.4 \mathrm{ng} / \mathrm{ml} ; 0.2 \mathrm{ng} / \mathrm{ml})$ for both time intervals in the UA group (Table 2), was less than that found in the MI group $(1.7 \mathrm{ng} / \mathrm{ml} ; 13.4 \mathrm{ng} / \mathrm{ml})$ for both intervals, and exceeded the recommended cut-off AMI value established by Tmimi et al. ${ }^{9}$ Thus, it could be regarded a superior marker for differentiation between UA and AMI. It has been shown in prior work ${ }^{10}$ that a slight elevation of cTnl (above the lowest detection limit of $\leq 0.19 \mathrm{ng} / \mathrm{ml}$ ) as established by Anwaruddin et al. ${ }^{4}$ ) is a valid predictor of adverse events in patients with ACS. Thus, the measurement of cTnl in patients with a clinical history consistent with ACS derives benefits regarding early invasive management

Table 7: Validity parameters for two types of tests combinations at the optimum cut-off value when used to predict acute MI differentiating it from unstable angina.

\begin{tabular}{|c|c|c|c|c|c|c|c|}
\hline \multirow[t]{2}{*}{$\begin{array}{l}\text { Positive if } \geq \\
\text { cut-off value }\end{array}$} & \multirow[t]{2}{*}{ Sensitivity } & \multirow[t]{2}{*}{ Specificity } & \multirow[t]{2}{*}{ Accuracy } & \multirow{2}{*}{$\begin{array}{l}\text { Matthew's } \\
\text { correlation } \\
\text { coefficient }\end{array}$} & \multicolumn{2}{|c|}{$\begin{array}{c}\text { PPV at pretest } \\
\text { probability = }\end{array}$} & \multirow{2}{*}{$\begin{array}{c}\text { NPV at } \\
\text { pretest } \\
\text { probability } \\
=10 \%\end{array}$} \\
\hline & & & & & $50 \%$ & $90 \%$ & \\
\hline $\begin{array}{l}\text { Combination of } \\
\text { troponin-I and } \\
\text { H-FABP at } \\
\text { optimum cut-off } \\
\text { value-first } 4 \text { hours }\end{array}$ & 73.3 & 100.0 & 83.6 & 0.716 & $\begin{array}{c}100 . \\
0\end{array}$ & 100.0 & 97.1 \\
\hline $\begin{array}{l}\text { Combination of } \\
\text { troponin-I and } \\
\text { H-FABP at } \\
\text { optimum cut-off } \\
\text { value-(6-12 hours) }\end{array}$ & 100.0 & 96.4 & 98.6 & 0.971 & 96.6 & 99.6 & 100.0 \\
\hline
\end{tabular}


strategies. The ROC curve analysis showed that cTnl has a ROC curve area of 0.820 (Table 5 ). This was significantly larger than that of the equivocal area (0.5) in the first interval, which indicates that troponin I is consistent as an indicator of AMI versus unstable angina. The higher the cut-off value, the more the sensitivity decreases, and the specificity increases. In the first interval ( $\leq 4 \mathrm{hrs}$ ), the optimum cut-off for cTnl was $1.25 \mathrm{ng} / \mathrm{ml}$, with a sensitivity of $53.3 \%$ and a specificity of $100 \%$ (Table 6 ). A slight insensitivity (a sensitivity of $53.3 \%$ ) gave early false negative results for cTnl, highlighting the need for multiple timed samples. The present study confirms the published data ${ }^{9}$, in that it was found this test was slightly poor in terms of sensitivity (i.e., some cases of AMI are missed) within the first interval following chest pain onset. In the first study interval, if the probability of having AMI versus unstable angina in patients with chest pain was $50 \%$, cTnl revealed $\mathrm{AMI}$ with a confidence level of $100 \%$, with equal or higher cut-off value $(1.25 \mathrm{ng} / \mathrm{ml})$.

Heart-type fatty acid binding protein (H-FABP)

In acute myocardial infarction, the sensitive indicator of ischemia, heart type fatty acid binding protein, may be considered a potential marker for early diagnosis ACS; this cardiac biomarker level increases well before markers for cardiac necrosis. ${ }^{11}$ It starts increasing within an hour following myocardial cell damage, and peaks between 6 and 8 hours post pain onset, returning to normal between 24 and 30 hours post pain onset. ${ }^{12} \mathrm{H}$-FABP levels $>7$ $\mathrm{ng} / \mathrm{ml}$ in patients presenting with chest pain is considered positive for $\mathrm{AMI}^{13}$, while in a study by Aktuğlu et al., ${ }^{14}$ normal levels of $\mathrm{H}-\mathrm{FABP}$ were stated to range between 0.24 and $2.55 \mathrm{ng} / \mathrm{ml}$. In this study, the mean concentration of H-FABP was $5.6 \pm 2.92 \mathrm{ng} / \mathrm{ml}$ and $5.2 \pm 2.46 \mathrm{ng} / \mathrm{ml}$ respectively for the two time intervals in unstable angina; this was significantly less than AMI means in both time intervals (10.5 $\mathrm{ng} / \mathrm{ml}$ and $16.4 \mathrm{ng} / \mathrm{ml}$ respectively - see Table 4). The above information reveals the means in both study intervals in the unstable angina group were higher than normal range and less than the AMI cut-off values. This potentially confirms our hypothesis regarding the usefulness of $\mathrm{H}-\mathrm{FABP}$ in diagnosing and differentiating unstable angina from $A M I$ in the early stages. The application of optimum cut-off values for both study biomarkers in the first time interval indicates the same efficacy for the ruling-in of $\mathrm{MI}$ (PPV, 100\%). However, $\mathrm{H}-\mathrm{FABP}$ also provided an important ruling-out of MI (NPV 94.6\%) (Table 6). Similar results have been observed by Reiter et al. $^{15}$ However, H-FABP levels measured at presentation were significantly higher in patients with AMI than those who were non-ST elevation myocardial infarction (NSTEMI). In contrast, the data of Alansari and Croal ${ }^{16}$ showed that H-FABP and myoglobin offer little clinical value, compared to cTnl, when measured at presentation in patients presenting with chest pain (3-12 hours).

Ischemia modified albumin (IMA)

In the present study, mean concentrations of IMA in both study time intervals in the UA group were higher than those in the AMI group, with a significant difference found in the second interval between the two groups (at $18.4 \mathrm{ng} / \mathrm{ml}, 16.6 \mathrm{ng} / \mathrm{ml}$ respectively - Table 3 ). As has previously been reported by Wudkowska et al. ${ }^{17}$ IMA concentrations do not differentiate ACS and NSTEMI patients from those with unstable angina.

The predictive power of troponin I and $\mathrm{H}-\mathrm{FABP}$ in combination, in diagnosing MI and differentiating it from unstable angina, at both time intervals

Application of a combined approach provides reasonable diagnostic discrimination for both the ruling-out (NPV) and the ruling-in (PPV) of $\mathrm{MI}$, including in patients presenting within the early hours of chest pain onset (30 min-4 hrs). The use of both biomarkers together, to their optimum cut-off value, provide 
a substantial improvement in sensitivity, $73.3 \%$ with $100 \%$ specificity, for the diagnosis of $\mathrm{Ml}$ and its differentiation from unstable angina, on admission, where the sensitivity was $53.3 \%$ for troponin I, and $48.9 \%$ for H-FABP when each one was used without other. Thus, it is recommended that this approach be applied for the first time interval, for early definitive diagnosis, with possible subsequent diagnostic or therapeutic interventions.

\section{Conclusion}

Troponin is an early discriminator between AMI and UA, and H-FABP showed reasonable validity for the same purpose, particularly when the suspected ACS patient is at the critical query period (first study interval). The validity of Troponin I and H-FABP as diagnostic biomarker increases with time and becomes more useful in confirming the diagnosis and differentiation of myocardial infarction from unstable angina by 6-12 hours after the onset of chest pain. Ischemia modified albumin (IMA) concentrations do not differentiate patients with acute myocardial infarction from patients with unstable angina. The approach of combining testing of troponin I with testing of H-FABP in the first 4 hours following the onset of chest pain seems promising for discriminating between patients with acute myocardial infarction and those with unstable angina. This approach may prove to be of clinical significance in the early diagnosis (ruling-in of $\mathrm{MI}$ ) and stratification of risk in patients with the acute coronary syndrome.

\section{Competing interests}

The authors declare no competing interests.

\section{References}

1. Anderson JL. ST segment elevation acute myocardial infarction and complication of myocardial infarction. In: Goldman L and Schafer Al, editors, Goldman's Cecil medicine, $24^{\text {th }}$ ed. Philadelphia: Elsevier Saunders; 2012. P. 434-47.

2. Nigam PK. Biochemical markers of myocardial injury. Indian J Clin Biochem 2007; 22:10-7.
3. Christenson $\mathrm{RH}$, Duh $\mathrm{SH}$, Sanhai WR. Characteristics of an albumin cobalt binding test for assessment of acute coronary syndrome patients: a multicenter study. Clin Chem 2001; 47:464-70.

4. Anwaruddin $S$, Januzzi JL, Baggish $A L$, Lewandrowski EL, Lewandrowski KB. Ischemia-modified albumin improves the usefulness of standard cardiac biomarkers for the diagnosis of myocardial ischemia in the emergency department setting. Am J Clin Pathol 2005; 123:140-5.

5. Gururajan P, Gurumurthy P, Nayar P, Nageswara GS, Cherian KM. Heart fatty acid binding protein (H-FABP) as a diagnostic biomarker in patients with acute coronary syndrome. Heart Lung Circ 2010; 19:660-4.

6. Lim W, Holinski P, Devereaux P. Detecting myocardial infarction in critical illness using screening troponin measurements and ECG recordings. Crit Care 2008; 12:36.

7. Thygesen K, Alpert JS, White HD. Universal definition of myocardial infarction. Eur Heart $\mathrm{J}$ 2007; 28:25-38.

8. Abebe A, Daniels J, Mckean JW, Kapenga JA. Statistics and Data Analysis. Western Michigan University: Kalamazoo Ml; 2001. P. 143-85.

9. Tamimi W, Alothaima A, Alhoda A, Dafterdar R. Evaluation of troponin $\mid$ in patients with acute myocardial infarction in the emergency department. J Clin Diagn Res 2010; 4:3170-5.

10. Sangita MP, Banker MP, Padalkar RK, Pathak PA, Bhagat SS, Ghone RA, et al. The Clinical Assessment of Ischaemia Modified Albumin and Troponin I in the Early Diagnosis of the Acute Coronary Syndrome. J Clin Diagn Res 2013; 7:804-8.

11. lida $K$, Nagao $K$, Uchiyama $T$, Kushiro $T$. Relationship between heart-type fatty acid-binding protein levels and the risk of death in patients with serious condition on arrival at the emergency department. Intern Med 2005; 44(10):1039-45.

12. Chan CP, Sanderson JE, Glatz JF, Cheng WS, Hempel A, Renneberg R. A superior early myocardial infarction marker. Human heart-type fatty acid-binding protein. Z Kardiol 2004; 93:38897.

13. Cavus U, Coskun F, Yavuz B, Ciftci O, Sahinere L, Aksoy $\mathrm{H}$, et al. Heart-type, fatty-acid binding protein can be adiagnostic marker in acute coronary syndromes. J Natl Med Assoc 2006; 98:1067-70.

14. Aktuğlu MB, Tunca $O$, Atalay $E$, Acar $S$, Erez SA, Namık YN, et al. Comparison of heart type free fatty acid binding protein, CPK-MB and troponin-I in the early diagnosis of acute coronary syndrome. Kafkas J Med Sci 2012; 2:109-14.

15. Reiter M, Twerenbold R, Reichlin T, Mueller M,Hoeller R, Moehring B, et al. Heart-type fatty acid-binding protein in the early diagnosis of 
The efficiency of cardiac biomarkers in the .......

acute myocardial infarction. Heart 2013; 99:70814.

16. Alansari SE, Croal BL. Diagnostic value of heart fatty acid binding protein and myoglobin in patients admitted with chest pain. Ann Clin Biochem 2004; 41:391-6.

17. Wudkowska A, Goch J, Goch A. Ischemia-modified albumin in differential diagnosis of acute coronary syndrome without ST elevation and unstable angina pectoris. Kardiol Pol 2010; 68:431-7. 